\title{
The Role of Fulvestrant in the Treatment of Metastatic Breast Cancer: A Case Report
}

\author{
Bánhegyi RJ ${ }^{1}$, Laczó $\mathrm{I}^{1^{*}}$, Fülöp $\mathrm{F}^{2}$, Mellár $\mathrm{E}^{2}$ and Pikó $\mathrm{B}^{1}$ \\ ${ }^{1}$ Oncology Centre, Pandy Kalman Bekes County Hospital, Hungary \\ ${ }^{2}$ Department of Radiology, Pandy Kalman Bekes County Hospital, Hungary
}

*Corresponding author: Ibolya Laczó Adress: Oncology Centre, Pandy Kalman Bekes County Hospital, Hungary, Tel: +36-66-526-526; Fax: +36-66-526-526; E-mail: laczoibolya@freemail.hu

Received date: March 22, 2014, Accepted date: April 28, 2014, Published date: May 05, 2014

Copyright: (c) 2014 Bánhegyi RJ, et al. This is an open-access article distributed under the terms of the Creative Commons Attribution License, which permits unrestricted use, distribution, and reproduction in any medium, provided the original author and source are credited.

\begin{abstract}
Nowadays we cannot find a cancer, in which the targeted therapy based on targeted diagnostics (immunohistochemistry, FISH, etc.) would not stand in the centre of the investigations. Breast cancer is not an exception either. Although the optimally performed surgery and the adequately planned radiotherapy are still important elements in the treatment of breast cancer and the achievement of effective local tumor control but their role has essentially changed in the last few years. In the treatment of patient who has been suffering from breast cancer for years either with or without his/her knowledge, the surgery should not be performed as soon as possible but when the patient "benefits" the most from this procedure. If distant metastases are present the removal of the tumor from the breast which means only the tip of the iceberg is absolutely unnecessary or it is required only in special cases. Systemic tumor control can be reached only by medicinal treatment. Regarding these treatments the importance of endocrine therapies (antiestrogens, aromatase inhibitors, LH-RH analogues etc.) traditional and modern chemotherapies (antracyclines, taxanes, platinum and pyrimidine derivatives, eribulin etc.) and the targeted biological therapies (trastuzumab, lapatinib, bevacizumab, olaparib etc.) can be emphasized. The targets of these biological therapies are either extracellular or intracellular molecular targets, such as estrogen receptor (tamoxifen, anastrazole, letrozole, exemestane, fulvestrant etc.) HER2 (trastuzumab, lapatinib, etc.), VEGF (bevacizumab, etc.) PARP (olaparib). It is well-known that due to frequent hormone sensitivity of breast cancer drugs influencing the hormonal effect are very effective. From these the importance of fulvestrant is discussed in our article. Based on literature data fulvestrant proved to be efficient both in locally advanced and metastatic breast cancers even if it was administered not as first (or second) line therapy.
\end{abstract}

Keywords: Hormone resistance; Fulvestrant; Long-term survival

\section{Introduction}

The hormone sensitivity of breast cancer and the idea of hormonal treatment have been known since the end of 19th century. Probably Schnizinger was the first, who suggested in 1889 the surgical removal of ovaries as a treatment in women suffering from breast cancer [1]. Following this in 1895 Beatson performed the first therapeutic bilateral oophorectomy and one year after this procedure reported about regression in locally advanced and metastatic breast cancer [2]. In the years of 1930 Taylor observed that the time to developing metastasis after mastectomy followed by bilateral ovarian irradiation prolonged [3]. These realizations created finally the basis of the hormone therapy of breast cancer. In the years of 1950 the surgical intervention and bilateral ovarian irradiation were routinely used as a part of adjuvant therapy and also in the treatment of metastatic breast cancer [4]. After these artificial castrations which were otherwise irreversible, the next big step in the hormonal therapy of breast cancer was the appearance of the drugs with reversible effects (anti-estrogens, GNRH analogs) in the second half of the 20th century. The anti-estrogen Tamoxifen, which was originally developed as a contraceptive and has residual estrogen effect as well, has been used successfully since 1973 for the treatment of breast cancer and even nowadays this is one of the most frequently ordered anticancer drugs [5]. It is suitable for the treatment of localized as well as metastatic breast cancer, even for chemoprevention [6].

There were great expectations to the efficacy of novel hormonal drugs, so-called "pure" anti-estrogens with no residual estrogen effect at all, appearing in the years of 1990, these expectations proved true to a certain extent. Administration of fulvestrant is indicated if breast cancer was proved to be sensitive for endocrine therapy, i.e. in hormone receptor positive breast cancer (ER: estrogen receptor, PR: progesterone receptor). It can be indicated both in clinically tumorfree status (for adjuvant therapy) and for the treatment of locally locoregionally advanced and metastatic breast cancer (for palliative therapy considering the summary of product characteristics and the financial regulations). Nowadays there are a lot of drugs available, called slightly inaccurately- hormone medications which are in fact chemically hormone related drugs, but regarding their mechanism of action they can be called as hormone receptor blocking drugs [7]. The adequate individual selection and the optimal administration sequence of these treatments raise a lot of questions among oncologists. However, there is now a broad professional consensus that a significant survival benefit can be observed with the administration of the modern, third generation aromatase inhibitors compared to the former drugs (progestagens and tamoxifen) [8]. Clinical studies supporting these findings were conducted around the turn of the millennium, when there were no data available about such hormone receptor blocking drugs like fulvestrant $[9,10]$. 
Fulvestrant decreases the effect of the body's own estrogen in several ways. Chemically it is a synthetic 17-beta estradiol analogue which binds to the estrogen receptor with similar affinity as the endogenous estradiol and this binding leads to an increased receptor degradation which results in a decrease of cell division normally induced by the own estradiol in the originally hormone sensitivecancer cells. Additionally, it inhibits the intracellular signal pathway responsible for the receptor associated cell proliferation which results in anti-tumorigenic effect as well [11]. Fulvestrant is a steroidal antiestrogen with a selective ER down-regulating (SERD) effect. In fact, it is a targeted drug, the target of which is the estrogen receptor. It is a competitive antagonist of the ER receptor binding to the estrogen receptor with high affinity and completely blocking its functions. Fulvestrant has a "pure anti-estrogen” effect which means it has no agonist, i.e. estrogen like effect on estrogen-receptor [12]. These chemical characteristics explain its high endocrine therapeutic efficacy. Patients responding well for the treatment show typically a long-term remission, probably the above mentioned estrogen receptor degradation effect stand in the background of postponing the resistance development. Its efficacy after tamoxifen resistance was proved by several investigations [11,12]. Administering fulvestrant in second or third line after anti-estrogen therapy proved to be more effective than the other hormone combinations (especially the progestagens), while in clinical studies administered as first line therapy it had equivalent effect than the other drugs (aromatase inhibitors, tamoxifen). The initial positive expectations were not supported by randomized early clinical studies (comparative studies with tamoxifen, anastrozole and exemestane which served as a basis in the registration procedure to certain extent), they confirmed only its equivalence with the above mentioned drugs [13-16]. Searching for its cause finally the (evidently negative) role of under-dosage was proved as a slightly significant survival benefit were observed in certain new clinical trials in which fulvestrant was administered in a monthly dose of 500-1000 mg instead of the previous $250 \mathrm{mg}[9,17,18]$. Several data refer to that the use of fulvestrant -similarly to other oncotherapiesmay offer more benefit for the patients regarding both the progression free and the overall survival, if it was administered differently from current financial Hungarian regulations, i.e. not only in palliative circumstances as salvage therapy but considering the adequate predictive factors - it could be an option in the early treatment which is otherwise permitted by the summary of the product characteristics $[19,20]$.

In Hungary the trade license of the drug was given first on 10. March 2004 and was renewed after 5 years. The active agent fulvestrant can be found only in one hormonal product in Hungary which is indicated according to the currently valid summary of product characteristics for the treatment of postmenopausal women with estrogen receptor positive, locally advanced or metastatic breast cancer for disease relapse during or after adjuvant anti-estrogen therapy, or disease progression on therapy with an anti-estrogen. In contrary to this the prescription availability is much more limited by the Hungarian National Health Insurance Fund: it can be prescribed in locally, locoregionally advanced or metastatic hormone receptor positive breast cancer in case of disease progression (defined as $25 \%$ increase in the size of the detected lesions or the development of new lesions) after treatment with tamoxifen and aromatase inhibitor - or aromatase inhibitor if the patient did not receive tamoxifen previously. After the first two week loading dose the drug is administered as $2 \times 250$ $\mathrm{mg}$ intramuscular injection monthly. The contraindications of its administration are limited to known hypersensitivity to its active agents or components, pregnancy, lactation and severe hepatic impairment. The most frequent side effects include: increase of liver enzyme levels (ALT, AST, ALP, sometimes GGT), elevation of serum bilirubin, nausea, vomiting, diarrhea, fatigue, headache, backache, hot flashes, skin rashes, allergic reactions, urogenital infections, thrombosis, and pulmonary embolism. The tightened lumen of the needle of pre-filled syringe in which the drug is distributed can provide the prescribed slow administration rate.

When administering fulvestrant arthralgia is reported less frequently compared to the use of aromatase inhibitors, hot flashes occur more often compared to tamoxifen and almost every side effects are less fess frequent than with use of progestagens.

\section{Methods}

After reviewing the literature data we searched for a patient in our practice in the treatment of whom the fulvestrant proved to be efficient after a second or third line treatment.

\section{Case Report}

In the Oncology Centre of Pandy Kalman Békés County Hospital numerous patients suffering from advanced breast cancer were treated successfully with fulvestrant during the last 8-9 years. In this report the case of an old menopausal woman (J.K.) treated with metastatic breast cancer and also suffering from hypertension will be presented.

The patient is now 66 years old, and she was screened by mammography in March 2010 because of suspicious right breast mass. After the mammography an ultrasound scan of breast and axilla was performed and a core needle breast biopsy was taken from the suspicious mass. Histology found an invasive ductal carcinoma with strong hormone receptor positivity (ER: 90\%, PR: 80\%), a HER2 immunhistochemistry $1+$ (that is negative) status. On the basis of the radiological examinations, in accordance with the physical examination, there was a $4-5 \mathrm{~cm}$ large irregular mass in the upper outer quadrant of the right breast and also enlarged nodes were detected in the right axilla. There was no metastasis detected by baseline staging examinations (chest X-ray, abdominal ultrasound scan, whole-body bone scintigraphy) and tumor markers (CEA, CA 15-3) were in normal range.

The patient at that moment was in good performance status (ECOG PS:0) with an appropriate cardiac status (LVEF: 66\%) therefore an epirubicine-paclitaxel (EPI-TAX) combination was started as neoadjuvant chemotherapy. After 2 cycles a significant regression was observed both in the primary tumor and the regional metastatic lymph nodes, therefore following a negative PET-CT scan mastectomy with axillary block dissection was performed in May 2010. The histological finding were accordant with the result of the core biopsy: an invasive ductal carcinoma was proved with a diameter of $2.2 \mathrm{~cm}$, strong ER and PR positivity, HER2 negativity, KI-67 was about $20 \%$. 3 out of 8 removed axillary lymph nodes found to be metastatic and in 1 an extension through the capsule could be detected. According to these findings the pathological TNM status was $\mathrm{pT} 2 \mathrm{pN} 1 \mathrm{aMx}$, so regarding the clinically M0 status the breast cancer was classified to IIB (early) stage.

Following this, based on the decision of our multidisciplinary team 3 cycles of epirubicine-cyclophosphamide (EC) and 3 cycles of paclitaxel (TAX) polychemotherapy were administered. Following the chemotherapy adjuvant hormonal therapy (anastrozole) was started 
and in November and December 2010 postoperative irradiation was performed. After completing the radiotherapy the patient was on continuous anastrozole therapy and came for follow up visits in every 3 months and underwent staging examinations required according to the protocol.

In October 2011, after one year treatment with of anastrozole hydrothorax was detected on the right side, causing dyspnoea, so following immediate puncture of pleural effusion a chest CT scan was performed which revealed a solitary pulmonary metastasis on the left side (Figure 1). The cytological examination of the pleural fluid supported our suspicion, it referred to pleural involvement. Meanwhile a whole-body bone scintigraphy proved multiple osseous metastases. Considering these findings parenteral ibandronic acid therapy and chemotherapy were started together with administration of low-molecular-weight heparin (LMWH). Between November 2011 and May 2012 the patient received altogether 8 cycles docetaxel and carboplatin (TXT-CBPL) combination as palliative chemotherapy and after a temporary stable disease a progression in the size of the lung metastasis was detected. At the same time the general status of the patient significantly worsened (ECOG PS: 2), anemia developed, due to which red blood cell transfusion was necessary several times. A Jamshidi bone marrow biopsy was already scheduled; however the patient was referred to the emergency department due to acute chest pain, where acute myocardial infarction was diagnosed. After short cardiology rehabilitation, in the middle of June we tried to administer tamoxifen therapy, but the patient did not tolerate it, she complained of insomnia, and therapy was stopped by herself.

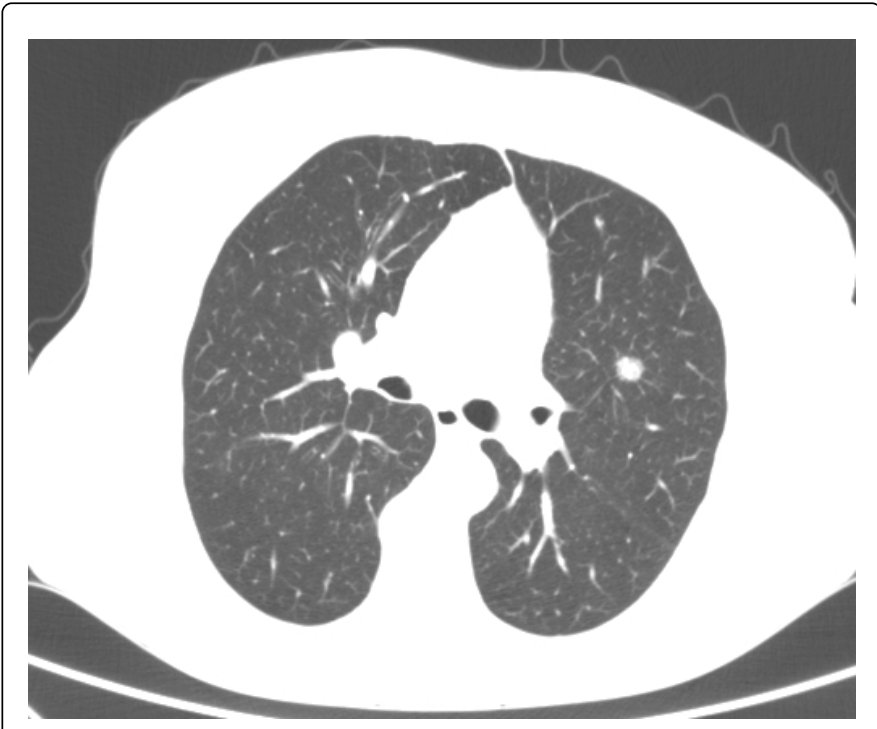

Figure 1: October 2011; solitary left pulmonary metastasis after one-year anastrazole treatment

Based on a new proposal of our multidisciplinary team at the beginning of July 2012 we started fulvestrant therapy. After the first 2week loading dose the patient has been receiving monthly $2 \times 500 \mathrm{mg}$ fulvestrant injections, the therapy resulted in complete remission regarding the pulmonary metastasis by April 2013 (Figure 2.), bone metastases showed stable status with the previously started bisphosphonate therapy. The patient performance status improved significantly during this period of time (ECOG PS: 1), there is no need for transfusions, and nowadays (February in 2014) she live almost a full-value life, only minimal help is needed for her everyday life.

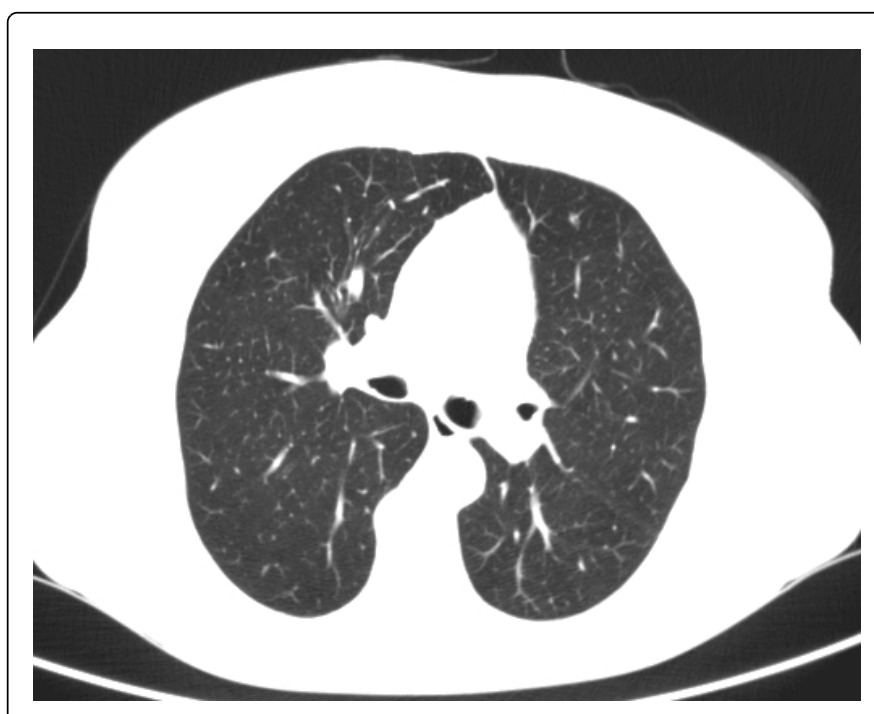

Figure 2: April 2013; Complete remission of the solitary pulmonary metastasis after 10-month fulvestrant treatment

\section{Conclusion}

We can conclude that in the complex treatment of strongly hormone dependent (ER positive in at least 50\%) and HER2 negative, locally-locoregionally advanced or metastatic breast cancers the endocrine therapy plays a central role in addition to the classic chemotherapies. If the tumor is locally advanced, but there are no distant metastases or there are distant metastases localized mainly to the bones and peripheral lymph nodes, visceral organs or body cavity lymph nodes are not or barely affected, or if the patient performance status is poor and/or the patient has severe co-morbidities or does not agree to receive chemotherapy endocrine therapy can be first choice of treatment. In case of extended visceral involvement with good cardiac and adequate performance status chemotherapy is the preferred first choice; hormonal treatments come into consideration only in second or third line. In our case with the relapse of breast cancer and becoming a metastatic disease we experienced both therapeutic situations. At the beginning, considering the patient's good performance and cardiac status and the pulmonary metastasis, we preferred the chemotherapy then after the patient's status worsened and she suffered a myocardial infarction, the hormonal therapy was preferred. 9 months after the introduction of fulvestrant therapy the staging examinations showed total regression of the pulmonary metastases and a stabile disease of the bone metastases, these results can be regarded as a significant success considering the more and more improving performance status of our patient as well.

\section{References}

1. Schinzinger A (1889) Über carcinoma mammae. Verh Dtsch Ges Chir 18: 28-29.

2. Beatson GT (1896) On the treatment of inoperable cases of carcinoma of the mamma: suggestions for a new method of treatment with illustrative cases. Lancet. 11: 104-107.

3. Taylor GW (1934) Artificial menopause in carcinoma of the breast. N Engl. J Med. 211: 1138-1140. 
4. Chen WY (2007) Az emlorák kezelése. In: Chen WY, Wardley A (szerk.): Emlorák (Dana-Farber Cancer Institute Handbook Series). Lélekben Otthon Kiadó Kft, Budapest: 85-92.

5. Kahán Zs, Bordás P (1996) Emlorák ma. Springer-Verlag Kiadó, Budapest: 105-131.

6. Bush TL, Helzlsouer KJ (1993) Tamoxifen for the primary prevention of breast cancer: a review and critique of the concept and trial. Epidemiol Rev 15: 233-243.

7. Nagykálnai T (2003) Az emlorák endokrin kezelése. Springer Tudományos Kiadó, Budapest: 13.

8. Mauri D, Pavlidis N, Polyzos NP, Ioannidis JP (2006) Survival with aromatase inhibitors and inactivators versus standard hormonal therapy in advanced breast cancer: meta-analysis. J Natl Cancer Inst 98: 1285-1291.

9. Di Leo A, Jerusalem G, Petruzelka L, Torres R, Bondarenko IN, et al (2010) Results of the CONFIRM Phase III trial comparing fulvestrant 250 $\mathrm{mg}$ with fulvestrant $500 \mathrm{mg}$ in postmenopausal women with estrogen receptor-positive advanced breast cancer. J Clin Oncol 28: 4594-4600.

10. Howell A, Bergh J (2010) Insights into the place of fulvestrant for the treatment of advanced endocrine responsive breast cancer. J Clin Oncol 28: 4548-4550.

11. Kahán Zs, Horváth Zs (2011) Emlorák. In: Kásler M (szerk.): Az onkológia alapjai (Egyetemi tankönyv). Medicina Könyvkiadó Zrt, Budapest: 918.

12. Nagykálnai T (2006) Az emlorák hormonális kezelése. In: Dank M, Demeter J (szerk.): Hatóanyagok, készítmények, terápia. Fókuszban az onkológia és az onkohematológia. Melinda Kiadó, Budapest: 139-158.

13. Howell A, Robertson JF, Quaresma Albano J, Aschermannova A, Mauriac L, et al. (2002) Fulvestrant, formerly ICI 182,780, is as effective as anastrozole in postmenopausal women with advanced breast cancer progressing after prior endocrine treatment. J Clin Oncol 20: 3396-3403.
14. Osborne CK, Pippen J, Jones SE, Parker LM, Ellis M, et al. (2002) Double-blind, randomized trial comparing the efficacy and tolerability of fulvestrant versus anastrozole in postmenopausal women with advanced breast cancer progressing on prior endocrine therapy: Results of a North American trial. J Clin Oncol 20: 3386-3395.

15. Robertson JF, Nicholson RI, Bundred NJ, Anderson E, Rayter Z, et al. (2001) Comparison of the short-term biological effects of 7alpha-[9(4,4,5,5,5-pentafluoropentylsulfinyl)-nonyl]estra-1,3,5,10)triene-3,17beta-diol (Faslodex) versus tamoxifen in postmenopausal women with primary breast cancer. Cancer Res 61: 6739-6746.

16. Robertson JF, Osborne CK, Howell A, Jonas SE, Mauriac L, et al. (2003) Fulvestrant versus anastrozole for the treatment of advanced breast carcinoma in postmenopausal women - a prospective combined analysis of two multicenter trials. Cancer 98: 229-238.

17. Kuter I, Hegg R, Singer CF, Badwer R, Lowe E (2008) Fulvestrant 500 mg vs. $250 \mathrm{mg}$ : First results from NEWEST, a randomized, phase II neoadjuvant trial in postmenopausal women with locally advanced, estrogen receptor-positive breast cancer. Breast Cancer Res Treat 109: 585-594.

18. Young OE, Renshaw L, Macaskill EJ, White S, Faratian D, et al. (2008) Effects of fulvestrant $750 \mathrm{mg}$ in premenopausal women with oestrogenreceptor-positive primary breast cancer. Eur J Cancer 44:391-399.

19. Nagy Zs (2010) Emlorákos betegek kezelése fulvesztranttal - lehetne hatékonyabb? Lege Artis Medicinae 20: 733-736.

20. Pritchard KI, Rolski J, Papai Z, Mauriac L, Cardoso F, et al. (2010) Results of a phase II study comparing three dosing regimens of fulvestrant in postmenopausal women with advanced breast cancer (FINDER2). Breast Cancer Res Treat 123: 453-461. 